\title{
Recovery of Cardiac Function After Living-Donor Lung Transplantation in a Patient With Primary Pulmonary Hypertension
}

\author{
Kengo Fukushima Kusano, MD; Hiroshi Date, MD*; Hideki Fujio, MD; \\ Katsumasa Miyaji, MD; Hiromi Matsubara, MD; Itaru Nagahiro, MD*; \\ Toru Satoh, MD**; Nobuyoshi Shimizu, MD*; Tohru Ohe, MD
}

\begin{abstract}
Legislation for brain death and organ transplantation was passed in Japan in 1997, but there is still a great shortage of brain-death donors. Primary pulmonary hypertension ( $\mathrm{PPH})$ is a progressive disease that is usually followed by death within 5 years of diagnosis. Continuous infusion of prostacyclin is effective, but some patients will ultimately require heart-lung or lung transplantation. The first case of bilateral living-donor lobar lung transplantation (LDLLT) for PPH in Japan is reported. The recipient was a 19-year-old woman who was diagnosed as PPH at the age of 14 years and began intravenous prostacyclin therapy. Initially her symptoms improved, but she returned to New York Heart Association class IV in 2000. In January 2001, she underwent bilateral LDLLT. Postoperative echocardiography showed that the right ventricular diameter had decreased and septal wall motion had normalized, resulting in a round-shaped left ventricle. Right heart catheterization demonstrated that cardiac output and pulmonary arterial pressure had normalized. The right ventricular ejection fraction improved from $15 \%$ to $77 \%$. The patient was discharged from hospital after 60 days postoperatively. LDLLT will become one of the options in Japan for end-stage PPH. (Circ J 2002; 66: 294-296)
\end{abstract}

Key Words: Cardiac function; Echocardiography; Living lung transplantation; Primary pulmonary hypertension

$\mathbf{P}$ imary pulmonary hypertension $(\mathrm{PPH})$ is a progressive disease of unknown etiology that is usually followed by death within 5 years (median, 2.8 years) of diagnosis! Right ventricular (RV) failure is commonly observed and is a prognostic variable of $\mathrm{PPH}^{2}$ Although significant advances in medical treatment of PPH have been achieved in the past decade by continuous intravenous prostacyclin therapy, 3 patients who are refractory to vasodilator therapy will ultimately require heart-lung or lung transplantation.

In Japan, legislation for brain death and organ transplantation was passed in 1997, but there is still a great shortage of brain-death donors. Living-donor lobar lung transplantation (LDLLT) is an alternative for end-stage lung disease ${ }^{4}$ and we report the first successful case of bilateral LDLLT for PPH in Japan.

\section{Case Report}

A 19-year-old woman had been diagnosed as having PPH at the age of 14 years and had started on continuous intravenous prostacyclin therapy. Initially her symptoms greatly improved, but they gradually deteriorated and despite highdose prostacyclin therapy $\left(140-160 \mathrm{ng} \cdot \mathrm{kg}^{-1} \cdot \mathrm{min}^{-1}\right)$, she

(Received April 9, 2001; revised manuscript received June 15, 2001; accepted June 19, 2001)

Departments of Cardiovascular Medicine and *Surgery II, Okayama University Medical School, Okayama and **Cardiopulmonary Division, School of Medicine, Keio University, Tokyo, Japan

Mailing address: Kengo Fukushima Kusano, MD, Department of Cardiovascular Medicine, Okayama University Medical School, 2-5-1 Shikata-cho, Okayama 700-8558, Japan. E-mail: kfuku@cc.okayamau.ac.jp returned to New York Heart Association class IV in 2000. She developed massive hemoptysis and was urgently admitted with signs of RV failure. Right heart catheterization revealed highly elevated pulmonary arterial pressure (PAP, systolic/diastolic/mean: 80/40/58 $\mathrm{mmHg}$ ) and a severely reduced cardiac index $\left(\mathrm{CI}, 1.4 \mathrm{~L} \cdot \mathrm{min}^{-1} \cdot \mathrm{m}^{-2}\right)$. High-dose inotropic therapy with diuretics was initiated. Repeat right heart catheterization 1 month later revealed a minor improvement in the CI, but a persistently high PAP (Table 1). Twelve-lead ECG revealed right atrial overload and RV hypertrophy (Fig 1). Echocardiography demon-

Table 1 Heart and Lung Function

\begin{tabular}{lcc}
\hline \hline & Preoperative & Postoperative \\
\hline $\mathrm{mRAP}(\mathrm{mmHg})$ & 8 & 0 \\
$\mathrm{RVEDP}(\mathrm{mmHg})$ & 17 & 2 \\
$\mathrm{PAP}(\mathrm{mmHg})$ & $84 / 48(58)$ & $33 / 12(19)$ \\
$\mathrm{mPCWP}(\mathrm{mmHg})$ & 11 & 8 \\
$\mathrm{SAP}(\mathrm{mmHg})$ & $90 / 48(74)$ & $119 / 76(90)$ \\
$\mathrm{CI}\left(\mathrm{L} \cdot \mathrm{min}^{-1} \cdot \mathrm{m}^{-2}\right)$ & 1.8 & 2.8 \\
$\mathrm{RVEF}(\%)$ & 15 & 77 \\
$\mathrm{PaO}(\mathrm{Torr})$ & $82\left(\mathrm{O}_{2} 4 \mathrm{~L} / \mathrm{min}\right)$ & $97($ Room air $)$ \\
$\mathrm{PaO} 2(\mathrm{kPa})$ & 10.9 & 12.9 \\
$\mathrm{PaCO}(\mathrm{Torr})$ & 25 & 40 \\
$\mathrm{PaCO}(\mathrm{kPa})$ & 3.3 & 5.3 \\
$\mathrm{FVC}(\mathrm{ml})$ & $\mathrm{NA}$ & 1,550 \\
$\mathrm{Predicted} \% \mathrm{FVC}(\%)$ & $\mathrm{NA}$ & 49.7 \\
\hline
\end{tabular}

mRAP, mean right atrial pressure; RVEDP, right ventricular end-diastolic pressure; PAP, pulmonary artery pressure; $M P C W P$, mean pulmonary capillary wedge pressure; SAP, systemic arterial pressure; $C I$, cardiac index (calculated Fick); RVEF, right ventricular ejection fraction obtained by radio nuclide scan; $\mathrm{PaO}_{2}$, arterial oxgen tension; $\mathrm{PaCO}_{2}$, arterial carbon dioxide tension; FVC, forced vital capacity. 


$$
\text { II mere V1 }
$$

Fig 1. 12-leads ECG before and after LDLLT. (Left) Before LDLLT, right atrial overload and RV hypertrophy can be seen. (Right) After transplantation, a moderate recovery of the right axis deviation in the QRS wave and a decrease in P-wave amplitude were observed. However, RV hypertrophy still remained.

strated a severely dilated and thickened RV wall with enlargement of the right atrium, and pulmonary artery and massive tricuspid regurgitation. Mild pericardial effusion was also observed. Left ventricular function was preserved, apart from flattening of the interventricular septum in the diastolic phase (Fig 2). The RV ejection fraction (RVEF) was $15 \%$ on first-pass nuclear angiography. The patient was bed-ridden and required continuous oxygen inhalation (4L/min).

In January 2001, she underwent LDLLT with a right lower lobe from her father (51 years old) and a left lower lobe from her mother (50 years old). Heights and weights were $157 \mathrm{~cm}$ and $38.0 \mathrm{~kg}$ for the recipient, $172 \mathrm{~cm}$ and 71.0 $\mathrm{kg}$ for the father, and $157 \mathrm{~cm}$ and $55.0 \mathrm{~kg}$ for the mother. During the early postoperative period, she was treated with various cardiovascular medications, such as intravenous dopamine, dobutamine, prostaglandin E1, phosphodiesterase III inhibitor and inhaled nitric oxide, and triple-drug therapy of tacrolimus, mycophenolate mofetil and prednisone for postoperative immunosuppresion. She was completely

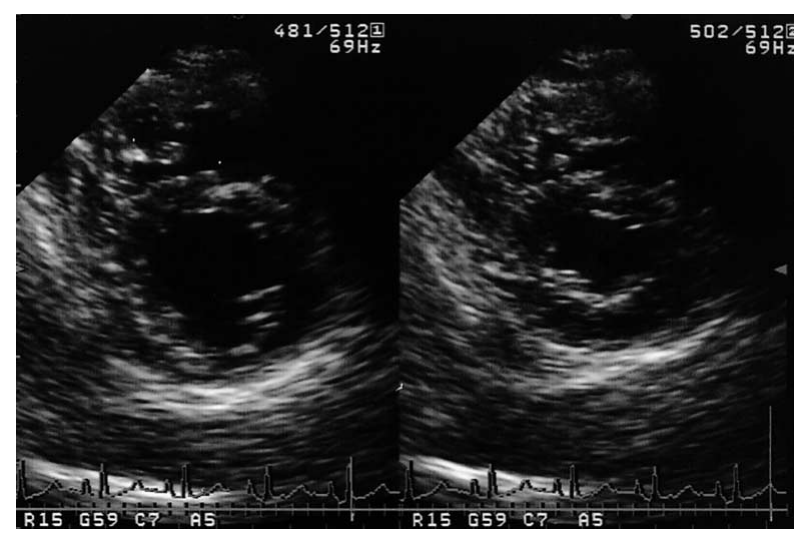

Fig 3. Echocardiography after LDLLT showing a marked decrease in the dimensions of the right ventricle, and a change in the shape of the left ventricle from D-shaped to round.

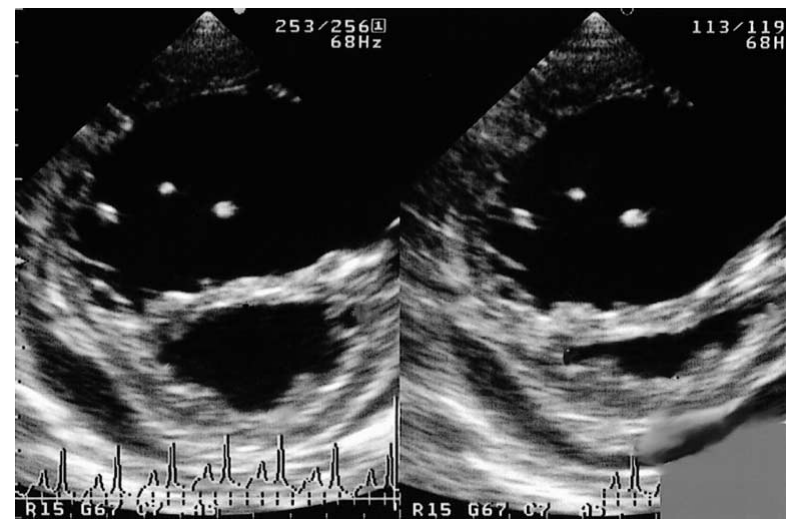

Fig 2. Echocardiography before LDLLT. The right ventricle is dilated and thickened, and abnormal septal wall motion is apparent. The left ventricle is D-shaped. There is mild pericardial effusion.

weaned from the respirator within 12 days and right catheterization performed on postoperative day 50 revealed a remarkable improvement in her hemodynamics (Table 1). The electrocardiographic changes were a moderate recovery of the right axis deviation in the QRS wave and a decrease in the P-wave amplitude (Fig 1). Echocardiographic changes included a decrease in the right atrial and ventricular diameters, recovery of the round shape of the left ventricle, normalization of septal motion and disappearance of the tricuspid regurgitation (Table 2, Fig 3). Her chest X-ray showed a decrease in the size of the cardiac silhouette (Fig 4). The RVEF had improved to $77 \%$ on firstpass nuclear angiography. Her forced vital capacity (FVC) became $1,550 \mathrm{ml}$, or $49.7 \%$ of her predicted FVC. She was discharged from the hospital 60 days after transplantation.

\section{Discussion}

PPH is a progressive disease of unknown etiology, characterized by increased pulmonary vascular resistance and elevated PAP. Morbidity and mortality are dependent on the consequent abnormalities in cardiac structure and function, which includes RV enlargement and hypertrophy, and ultimately, RV failure is the cause of death in approximately two-thirds of patients with PPH. Median survival is 2.8

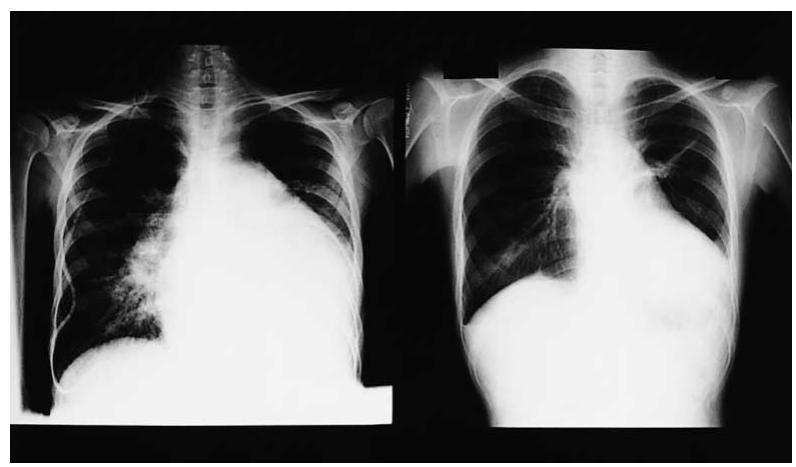

Fig 4. Chest X-rays before and after LDLLT. (Left) Before transplantation, there is severe enlargement of the cardiac silhouette (cardiothoracic ratio: 67\%). (Right) After transplantation, there is a marked decrease in the cardiac silhouette (cardiothoracic ratio: 55\%) and well-expanded grafts filling the chest cavity. 
years from the time of diagnosis, 1,2 The continuous infusion of prostacyclin (Epoprostenol) has significantly reduced mortality rates from PPH in the last decade, 3 and blade septal septostomy (BAS) has also resulted in clinical improvement in patients with PPH5 However, patients who are refractory to vasodilator therapy (the present patient was refractory to high-dose prostacycline therapy) or are unsuitable for BAS will require heart-lung or lung transplantation. Because of the severe shortage of brain-dead lung donors in Japan, the realistic option for the present patient was LDLLT4 In 1998, Shimizu et al reported the first case of LDLLT for pulmonary ciliary dyskinesia in Japan ${ }^{6}$ and the present case is the first case in Japan in which PPH was successfully treated by LDLLT.

After the operation, the cardiac function of the patient recovered dramatically. Echocardiography showed that both the right atrial and ventricular diameters had decreased, septal wall motion had normalized and the RVEF had also normalized, all of which resulted in a rounded left ventricle. Right heart catheterization demonstrated that PAP and $\mathrm{CO}$ had normalized. Starnes et al reported successful LDLLT in 4 PPH patients, including 3 Japanese children, but did not discuss the cardiac function after the operation? Kramer et al reported the recovery of right ventricular function at 6 months after single lung transplantation, showing that improved pulmonary hemodynamics after single-lung transplantation for PPH or Eisenmenger's syndrome results in reversal of right heart dilatation and dysfunction and improvement in myocardial performance. Our observations were quite similar to their findings, except that our patient recovered PAP and RV function within 2 months. We hope that LDLLT will become an option in Japan for end-stage PPH.

\section{References}

1. D'Alonzo GE, Barst RJ, Ayres SM, Bergofsky EH, Brundage BH, Derte KM, et al. Survival in patients with primary pulmonary hypertension: Results from a national prospective registry. Ann Intern Med 1991; 115: 343-349.

2. Rich S, Dantzker DR, Ayres SM, Bergofsky EH, Brundage BH, Detre KM, et al. Primary pulmonary hypertension: A national prospective study. Ann Intern Med 1987; 107: 216-223.

3. Barst RJ, Rubin LJ, Long WA, McGoon MD, Rich S, Badesch DB, et al. A comparison of continuous intravenous epoprostenol (prostacyclin) with conventional therapy for primary pulmonary hypertension. N Engl J Med 1996; 334: 296-302.

4. Date H, Nagahiro I, Aoe M, Sano Y, Andou A, Shimizu N. Referrals for lung transplantation in Japan: Unique indications and necessity of living-donor lobar lung transplantation. Jpn J Thorac Cardiovasc Surg 2000; 48: 335-338.

5. Takigiku K, Shibata T, Yasui K, Iwamoto M. Successful blade atrial septostomy in a patient with severe primary pulmonary hypertension: A case report. Jpn Circ J 1997; 61: 877-881.

6. Shimizu N, Date H, Yamashita M, Aoe M, Nagahiro I, Yoshikawa T, et al. First successful bilateral living-donor lobar lung transplantation in Japan. Nippon Geka Gakkai Zasshi 1999; 100: 806-814.

7. Starnes VA, Barr ML, Schenkel FA, Horn MV, Cohen RG, Hagen JA, et al. Experience with living-donor lobar transplantation for indications other than cystic fibrosis. J Thorac Cardiovasc Surg 1997; 114: $917-922$.

8. Kramer MR, Valantine HA, Marshall SE, Starnes VA, Theodore J. Recovery of the right ventricle after single-lung transplantation in pulmonary hypertension. Am J Cardiol 1994; 73: 494-500. 